Highlights

Exploring the development of mental rotation and computational skills in elementary students through educational robotics

Pascual D. Diago*, José A. González-Calero, Dionisio F. Yáñez

- Robotic map-reading tasks promote significant gains in CT in 8-year-old students

- Bee-bot produces significant improvements in CT compared to traditional instruction

- Bee-bot enhances CT for the 3rd grade students through map-reading task
International Journal of Child-Computer Interaction $x x x$ $(x x x x) x x x$

Graphical abstract and Research highlights will be displayed in online search result lists, the online contents list and the online article, but will not appear in the article PDF file or print unless it is mentioned in the journal specific style requirement. They are displayed in the proof pdf for review purpose only. 
Research paper

\title{
Exploring the development of mental rotation and computational skills in elementary students through educational robotics
}

\author{
Pascual D. Diago ${ }^{\text {a,* }}$, José A. González-Calero ${ }^{b}$, Dionisio F. Yáñez ${ }^{c}$ \\ a Departament de Didàctica de la Matemàtica, Universitat de València, València, Spain \\ ${ }^{\mathrm{b}}$ Departamento de Matemáticas, Universidad de Castilla-La Mancha, Albacete, Spain \\ ${ }^{\mathrm{c}}$ Departamento de Matemáticas, Universitat de València, València, Spain
}

\section{A R T I C L E I N F O}

\section{Article history:}

Received 8 January 2021

Received in revised form 12 August 2021

Accepted 16 August 2021

Available online $\mathrm{xxxx}$

\section{Keywords:}

Educational robotics

Computational thinking

Mental rotation

Bee-bot

Elementary education

Tangible user interface

\begin{abstract}
A B S T R A C T
Interest in educational robotics has increased over the last decade. Through various approaches, robots are being used in the teaching and learning of different subjects at distinct education levels. The present study investigates the effects of an educational robotic intervention on the mental rotation and computational thinking assessment in a 3rd grade classroom. To this end, we carried out a quasi-experimental study involving 24 third-grade students. From an embodied approach, we have designed a two-hour intervention providing students with a physical environment to perform tangible programming on Bee-bot. The results revealed that this educational robotic proposal aimed at mapreading tasks leads to statistically significant gains in computational thinking. Moreover, students who followed the Bee-bot-based intervention achieved greater CT level compared to students following a traditional instruction approach, after controlling student's prior level. No conclusive results were found in relation to mental rotation.
\end{abstract}

(c) 2021 Published by Elsevier B.V.

\section{Introduction and aims}

Nowadays, computer programming is an emerging discipline which is being introduced in the early years of formal education (e.g. Çiftci \& Bildiren, 2020; Govind, Relkin, \& Bers, 2020; Grover, Jackiw, \& Lundh, 2019; Rodríguez-Martínez, GonzálezCalero, \& Sáez-López, 2020). Among other approaches, programming is being taught to young learners through educational robotics (ER) (Anwar, Bascou, Menekse, \& Kardgar, 2019; Benitti, 2012). In 2017, ER was signalled as one of the emerging technologies with the greatest possibilities for application in educational contexts in the short term ( 1 or 2 years) (Freeman, Adams Becker, Cummins, Davis, \& Hall Giesinger, 2017). Since then, ER have been present at all educational levels, from kindergarten to university (e.g. Kim, et al., 2015; Lindh \& Holgersson, 2007; MerinoArmero, González-Calero, Cózar-Gutiérrez, \& Villena-Taranilla, 2018; Sisman, Kucuk, \& Yaman, 2020; Sullivan \& Bers, 2016).

One of the main purposes of ER usage in K-12 education is to offer opportunities for children to actively construct knowledge and transfer skills (Anwar et al., 2019). ER is presented as an innovative learning environment, enhancing problem-solving abilities and higher order thinking skills (Atmatzidou \& Demetriadis,

\footnotetext{
* Correspondence to: Departament de Didàctica de la Matemàtica, Facultat de Magisteri - Campus de Tarongers, Avda. Tarongers, 4, 46022 València, Spain. E-mail addresses: Pascual.Diago@uv.es (P.D. Diago),

Jose.GonzalezCalero@uclm.es (J.A. González-Calero), Dionisio.Yanez@uv.es (D.F. Yáñez)
}

2016; Hussain, Lindh, \& Shukur, 2006). Different authors include different cognitive processes and skills related to coding when describing what makes up computational thinking (CT). Initiatives integrating CT-based activities through ER are growing in popularity amongst early education researchers and educators (Benitti, 2012; Sullivan \& Bers, 2016). Furthermore, the research literature is pointing towards ER as a potential tool to foster CT skills in young children (Bers, Flannery, Kazakoff, \& Sullivan, 2014; Chen, et al., 2017; Merino-Armero et al., 2018).

From a pedagogical standpoint, the educational practices of kindergarten and the early years of primary school are usually based on physical and sensory-motor experience. According to classic authors in this field, such as Piaget, Bruner or Fischbein, these concrete, situated, and action-based practices provide children with a conceptual embodiment that begins with interactions with real-world objects and develops in sophistication through verbal descriptions and definitions (Lakoff \& Núñez, 2000; Tall, 2013). In this context, ER provide classrooms with hands-on experiences, allowing children to construct their own learning and facilitating cognitive as well as fine sensory-motor development (Bers, Seddighin, \& Sullivan, 2013; Papert, 1980). Many of these novel robotic kits are inspired by traditional educational manipulatives typically found in schools, such as Froebel's "gifts", Montessori materials or Nicholson's loose parts (Bartolini \& Martignone, 2020; Sullivan, Strawhacker, \& Bers, 2017).

Our study frames the CT abilities in the real physical context offered by ER. In the present study we used the physical 
robot Bee-bot, a special floor robot with directional controls, as a sensory-motor instrument which has to be programmed in order to complete map-based route finding activities. Tangible experience in the early school years, through activities based on floor robots, are commonly conducted according to an embodied and enacted approach (Città, et al., 2019; Sabena, 2017; Strawhacker \& Bers, 2015). The literature provides evidence that ER promotes spatial abilities in students due to inherent geometric and spatial concepts explored when programming the movements of a robot (space perception, space conceptualisation and general spatial abilities, especially concerning mental rotation skills) (González-Calero, Cózar, Villena, \& Merino, 2019; Julià \& Antolì, 2018; Merino-Armero et al., 2018; Sisman et al., 2020). Some studies have investigated the connections between spatial reasoning and $\mathrm{CT}$, suggesting that both thinking abilities are reciprocally related (Ambrosio, Almeida, Macedo, \& Franco, 2014; Città, et al., 2019; Román-González, Pérez-González, \& JiménezFernández, 2017). Based on this framework, this study aims to answer the following research questions:

(RQ1) Does an ER-based intervention promote greater gains in computational thinking and mental rotation abilities in 8-year-old students compared with traditional instruction?

(RQ2) Do 8-year-old students who followed an ER-based intervention achieve greater computational thinking and mental rotation ability levels compared to students following a traditional instruction approach, after controlling students' prior levels?

\section{Literature review and fundamentals}

\subsection{Computational thinking framework}

The term computational thinking (CT) first appeared in 2006 as a set of analytical processes rooted in computer science and programming activity (Wing, 2006). In its primary definition, it involves thinking recursively, applying abstraction, splitting a complex problem into smaller parts, and using heuristic reasoning to find a solution (Wing, 2006, 2010). At present, a large number of definitions for CT have been proposed, without any consensus (Grover \& Pea, 2013; Román-González et al., 2017; Shute, Sun, \& Asbell-Clarke, 2017). Despite this lack of a generally agreed-upon definition for CT, it seems to be clear that CT integrates reasoning skills, which enhance and reinforce intellectual abilities and, therefore, are transferable to different domains (Wing, 2014). Various instruments for the assessment of CT have emerged together within these different views of CT (Brennan \& Resnick, 2012; Román-González et al., 2017; Shute et al., 2017; Weintrop, Coenraad, Palmer, \& Franklin, 2019). Based on this emerging context, in the present study we consider CT as part of human thought, intimately related to problem solving from a computational viewpoint. In this way, CT can be considered as a procedure that combines computational and inherently human skills, resulting in a synergic process for solving problems.

\subsection{Spatial skills: mental rotation}

Spatial ability can be defined (or understood) as a construct that encompasses the skills "to generate, retain, retrieve and transform well-structured visual images" (Lohman, 1996). Although there is no complete agreement about the terminology (Gutiérrez, 1996), it can be understood as the ability to "perceive and understand spatial relationships, to visualise spatial stimuli such as objects, and to manipulate or transform them in some way" (Reilly, Neumann, \& Andrews, 2017, p. 196). Consequently, the term visualisation is also used as a synonym for spatial thinking. Therefore, Gutiérrez (1996) considers visualisation "as the kind of reasoning activity based on the use of visual or spatial elements, either mental or physical, performed to solve problems or prove properties".

Spatial reasoning is understood to be composed of different abilities, with mental rotation (MR) being one of them. According to Shepard and Metzler (1971), MR is the ability to mentally rotate 2 - or 3-dimensional objects in the mind. MR is commonly described as a shape-matching task between two elements (e.g. objects, pictures or positions), in which in order to make the required comparison, individuals first have to imagine one element as rotated into the same orientation as the other one (Shepard \& Metzler, 1971). Spatial tasks that aim to stimulate MR commonly present dissimilar elements showing disparities in orientation or position, varying in the degree of rotation, translation, or being mirror images (Hawes, Tepylo, \& Moss, 2015). Everyday activities such as manipulating and recognising objects, reading maps or planning routes (tasks addressed in our study), require the use of these visio-spatial abilities (Davis \& The Spatial Reasoning Study Group, 2015; National Council of Teachers of Mathematics, 2000; Tzuriel \& Egozi, 2010), especially MR.

\subsection{Educational Robotics: Bee-bot}

At present, a wide variety of physical robots exist for all levels of education with many different purposes (Hamilton, ClarkeMidura, Shumway, \& Lee, 2020). Research has shown that ER activities can be effective in developing skills such as critical thinking, creative thinking, problem-solving, teamwork, decision making or following a scientific process (Benitti, 2012; Bers et al., 2014; Eguchi, 2014; Highfield, 2010; Verner, 2004). Related to this, with an ER approach children actively engage with powerful ideas from computer science and robotics, including the core concepts of CT. In particular, young learners can take their first steps into developing CT with ER-based interventions (Bers, 2008; Bers et al., 2014). Concerning spatial abilities, recent studies have analysed the possibilities of ER interventions devoted to foster these skills (Benitti, 2012; Coxon, 2012; Sisman et al., 2020). The literature has reported results concerning the effectiveness of ERbased instruction for the development of MR abilities, specifically related to floor robots (González-Calero et al., 2019; Julià \& Antolì, 2018; Sabena, 2017). As mentioned by Città, et al. (2019), the skills put into play when programming the movement of a floor robot involve body actions that connect cognitive processes and knowledge of the environment and space.

Bee-bot is one of the most well-known floor robots in elementary and primary education (Schina, Esteve-Gonzalez, \& Usart, 2021). With a likeable bee-shape (Fig. 1), it has been categorised as "Button-Operated Robot" (Hamilton et al., 2020). Bee-bot has physical buttons on the device itself which can be pressed sequentially by the user to program the robot to move in specific directions. Usually, the inclusion of Bee-bot in education interventions is addressed to develop coding skills (Kazakoff, Sullivan, \& Bers, 2013; Stoeckelmayr, Tesar, \& Hofmann, 2011), cognitive skills related with problem-solving and cognitive flexibility (Di Lieto, et al., 2017; Diago, Arnau, \& González-Calero, 2018a, 2018b), visuo-spatial abilities (Sabena, 2017) or to initiate algebraic thinking through patterning (Inchaustegui \& Alsina, 2020).

As a simplified version of its early ancestor, the Logo Turtle Papert (1980), Bee-bot responds to simple movement commands presented as physical buttons (Fig. 1, centre): Turn right (Turn left): turn 90 degrees clockwise (anti-clockwise) whilst remaining in the same position; Forward (Backward): a straight-line movement of $15 \mathrm{~cm}$ forward (backward); Pause: stops the movement for $1 \mathrm{~s}$; Clear: removes all the previously sequenced instructions; 


\section{ARTCLE IN PRESS}
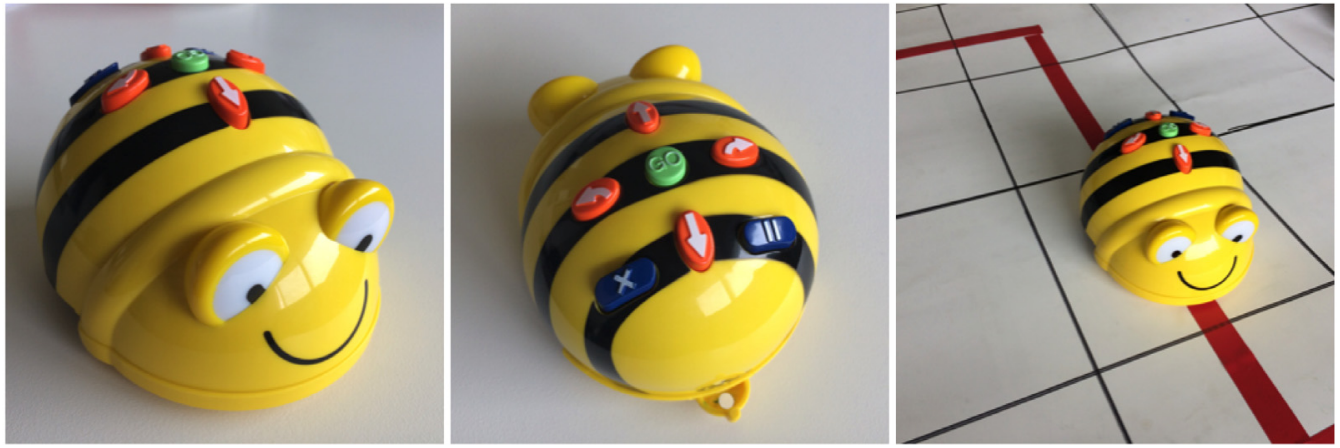

Fig. 1. Bee-bot robot (left). Physical buttons of Bee-bot (centre). $15 \mathrm{~cm}$-grid board for Bee-bot (right).

and GO: executes the sequenced instructions. As shown in the right panel of Fig. 1, the usual tasks to be completed with Beebot consist of boards with a $15 \mathrm{~cm}$ grid. Given its nature, activities carried out with Bee-bot are usually associated with visuo-spatial and problem-solving content, as will be discussed in the following sections.

\subsubsection{Body syntonic geometry}

From a psychological standpoint, cognitive and linguistic research has focused on the role of embodied resources, such as gestures and body postures, in thinking processes (McNeill, 1992, 2005). The case of mathematics education is no different, and in recent years the study of gestures and embodied resources has gained ground in different contexts, in particular problemsolving (Nemirovsky \& Ferrara, 2009; Radford, 2009).

On the one hand, the grid provided with Bee-bot activities helps the children to better conceptualise the space that surrounds the robot (Sabena, 2017). This helps when the student thinks about the instructions that have to be programmed to move the robot to a particular point. With this in mind, Bee-bot activities can become grounding pillars for more abstract knowledge conceptualisation, as they connect perception and manipulative experiences relating to the body and the surrounding space (Lakoff \& Núñez, 2000).

On the other hand, Bee-bot requires children to employ different programming instructions corresponding to robot-related movements (enhanced with sounds and flashing lights to favour visual perception). Those movements are relative to the reference system of the robot itself. There are clear parallels here with the Logo Turtle (Papert, 1980), mainly concerning body syntonic geometry. In this sense, the programming of Bee-bot hinges on the body syntonic nature of the robot, allowing the child to see him/herself as the robot. In Papert's words, regarding the Logo Turtle (Papert, 1980, p. 55), "a Euclidean point is at some place - it has a position, and that is all you can say about it. A Turtle is at some place - it, too, has a position - but it also faces some direction - its heading. In this, the Turtle is like a person - I am here and I am facing north - or an animal or a boat". As pointed out, due to the particular embodied interaction between the robot and the programmer, spatial skills will play a key role on the success in the tasks (Diago et al., 2018b; Diago, González-Calero, \& Arnau, 2019; Sabena, 2017). This is especially true when the reference systems of Bee-bot and the children do not coincide (i.e. when the robot is not oriented parallel to and with the same orientation as the children) (Diago et al., 2018b; Sabena, 2017). Thus, the use of Bee-bot in educational contexts is firmly related to children's sense and knowledge about their own bodies, enhancing embodied and performative aspects of children's interaction and learning (Papert, 1980; Sabena, 2017). In line with Papert's thoughts on the Logo Turtle (Papert, 1980), Bee-bot could serve as a transitional object in the process of internalising mathematical ideas, providing learners with the means to think about what they are doing. More importantly, it makes possible the presentation of geometry and mathematical concepts as an activity instead of a ready-made mathematics.

\subsubsection{Tangible programming}

Classic authors, e.g. Bruner or Dienes, emphasised the importance of practical activity and concrete models, especially at early educational levels. Concerning mathematics education, manipulatives have shown to be the connection between concrete and abstract mathematical ideas (Bartolini \& Martignone, 2020; Hodgen, Foster, Marks, \& Brown, 2018). In the case of mathematic-related manipulatives, Baroody (2017) places the focus on concrete experiences where a manipulative is pedagogically meaningful (Baroody, 2017). Following this approach, since the end of the 20th century different tangible programming interfaces have been designed to be used in educational settings (McNerney, 2004). Some ER-based proposals aim to provide children with meaningful and appropriate programming experiences without the need for computer screens or keyboards (McNerney, 2004). In these interfaces, children use different kinds of objects (blocks, beads, balls, etc.) to build physical computer programs (Bers, 2008; M., et al., 1998; McNerney, 2004). The tangible programming environments Electronic Blocks (Wyeth, 2008), Tern (Horn, Crouser, \& Bers, 2012) or KIBO (Bers, 2018) are examples of this category. A common characteristic of these physical environments is that the traditional mouse and keyboard interfaces are replaced with a tangible-manipulative interface, addressed to offer a combination of computer programming experience in, and, with the physical world (Horn et al., 2012). Moreover, the programming commands are provided in natural language (verbal or pictorial), usually in a building block-format in which children are able to create programs from the physical interactions provided by the blocks. Nowadays, these tangible programming interfaces are considered part of the ER panorama, especially oriented to kindergarten and school children (Bers, 2008).

As described previously, programming on Bee-bot is carried out by sequentially pressing the buttons on the robot itself. This configuration, in which we only have the robot, does not allow a true tangible programming activity, since the only way to think about the complete program is through the user's ability to remember the sequenced instructions. Thus, programming directly on Bee-bot does not provide the child "objects-to-thinkwith" (Papert, 1980), at least, not in a tangible or sensory way.

As our study aims to investigate the effect on CT from an embodied approach, we provide Bee-bot with a physical environment within which children can perform the tangible programming. To this end, we followed the approach by Perlman (1976) concerning the Logo Turtle (Perlman, 1976); along with the Bee-bot robot we provide the children with a physical set of cards corresponding to the robot's movements (Fig. 2, top) (Diago 


\section{$A R T C L E I N \quad P R E S S$}

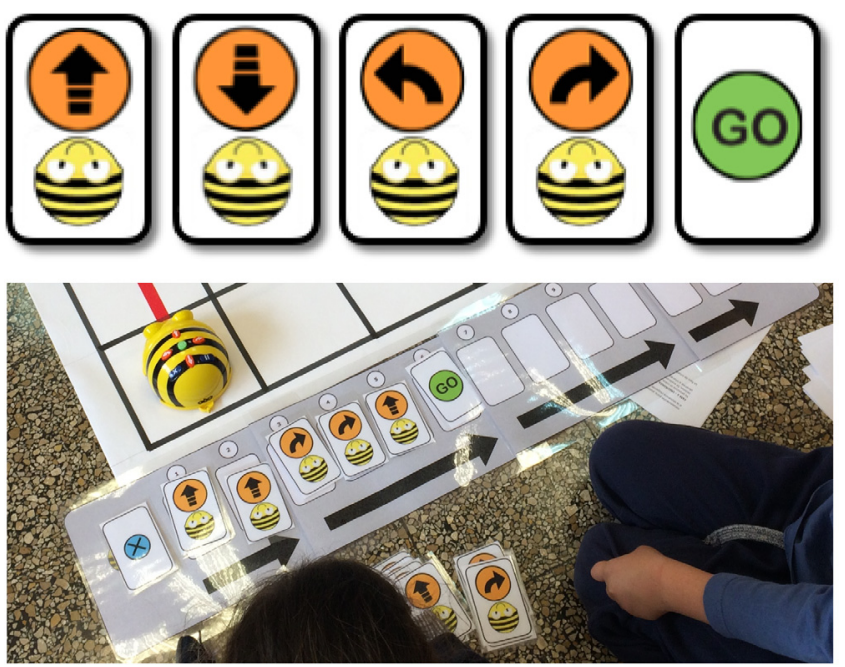

Fig. 2. Cards corresponding to the Bee-bot self-referenced system (top) and physical box to create the Bee-bot program (bottom).

et al., 2018a, 2018b). Each card acts as a physical instruction block. Before pushing any of the buttons on Bee-bot, the children were invited to draw up a program by sequencing cards in a physical "box" directly, adding, rearranging, and removing cards by hand (Fig. 2, bottom). The programming ended when the children added the card GO. At this moment, the commands in the box were translated to the Bee-bot which executed the corresponding movements. Thus, within this approach we can consider the set formed by Bee-bot and the card-box as a "Tangible User Interface" (Strawhacker \& Bers, 2015).

As stated, the role of the cards and the box here is to serve as a heuristic tool (in Polya's sense) (Diago et al., 2018a, 2018b). In this view, the provided physical cards and box facilitate both the planning and the debugging processes of programs in the Bee-bot environment. Furthermore, foreseeing the movements of Bee-bot, and afterwards checking the movements based on their choices by tracking the robot's movement path, offers a suitable context for stimulating and developing heuristic strategies and control processes, which are considered the basis of problem solving (Diago et al., 2018b, 2019; Sabena, 2017).

\section{Method}

\subsection{Design}

The study was configured as a quasi-experimental study as all the participants were part of a natural group (Cook \& Campbell, 1979). In order to assess children's prior and subsequent level regarding $\mathrm{CT}$ and $\mathrm{MR}$, we employed a pre-test/post-test design, before and after the intervention. Based on previous studies (González-Calero et al., 2019; Merino-Armero et al., 2018), we designed an intervention in the context of map-based route finding activities. As described in the study carried out by GonzálezCalero et al. (2019), the activities were designed from the basis of the type of tasks usually posed in 3rd Grade Primary textbooks. These activities, as part of the Social Sciences curricula, address contents related to map-reading, orientation, sense of direction, location and route-planning. Considered as spatial tasks, mapbased activities also include a realistic and meaningful context for primary students (Diezmann \& Lowrie, 2008). Moreover, mapbased route finding activities can be considered an appropriate approach to foster not only the acquisition of spatial abilities, but also CT skills related to route-instruction sequencing, route planning or route optimisation (González-Calero et al., 2019).

As described below, the participants were divided into an experimental and a control group. In our design, the experimental group used the tangible user interface made up of Beebot and the card-box system to complete the map-reading and directions tasks. The control group worked using a paper-andpencil format on maps and directions (Fig. 3). The intervention lasted, intentionally, only $2 \mathrm{~h}$ in order to fit within the frame usually devoted to map-reading activities in primary school classrooms (González-Calero et al., 2019).

\subsection{Participants}

The study sample group was made up of a total of 24 children ( $50 \%$ female) attending the 3rd grade of primary school in a public school in València (Spain). The age of the students ranged between 8 years 1 month and 9 years 1 month $(M=8$ years 6 months, $s d=10$ months). In order to obtain an accurate measure of the effect of the ER-based intervention, the participants were randomly assigned to the experimental and control groups. There were 12 students in both the control group and the experimental group ( 7 boys and 5 girls in the control group, and 5 boys and 7 girls in the experimental group). The teacher in charge of the class stated that none of the students had had previous experience with ER or coding activities.

\subsection{Data acquisition instrument}

In order to measure the students' CT skills and MR ability before and after the intervention phase, we used an instrument adapted from a validated CT assessment test (Román-González et al., 2017) along with the Map Test for Children (Peter, Glück, \& Beiglböck, 2010). Below, we justify the suitability of the items used. The instrument consisted of 18 items, 7 related to CT and 11 related to MR. These items made up both the pre-test and posttest. The experimental and control groups took the same pre-test and post-test. All the items were evaluated in a binary way, as either correct or incorrect.

\subsubsection{CT items}

Measurements of the students' CT acquisition were done by means of items from the validated test developed by RománGonzález et al. (2017). This test evaluates different dimensions of CT. Since the original test is for students ranging from 5 th to 10th Grade, we adapted it to 3rd Grade students, taking only the items related to the following components: basic directions and sequences, loops - repeated times and loops - repeated until. The CT test items are presented in pictorial representation (using arrows) or natural language (using verbal descriptions). In the end, we used a total of 7 items (Fig. 4, left, shows a sample of a used item).

\subsubsection{MR items}

The assessment of MR ability was done by means of an adaptation of the Map Test for Children (Peter et al., 2010). This test, developed for kindergarten and elementary school children, aims to assess the understanding of symbolic representations, the use of spatial relationships and the use of mental rotations; all fundamental components of map reading and map use. For each item, the test shows two views of a simplified fictitious city with different buildings. In one of the views, one building is identified with a red dot, and the individual has to identify the corresponding building in the other view. For this study, we selected items where the views were not aligned, so the children were forced to use mental rotation skills in order to identify the link between the two different views of the same building. We used 11 items (Fig. 4, right, shows a sample of a used item). 


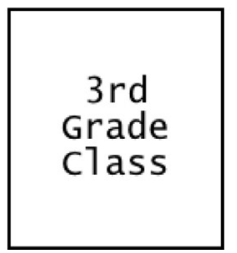

Experimental group
12 students
Control group
12 students

pre

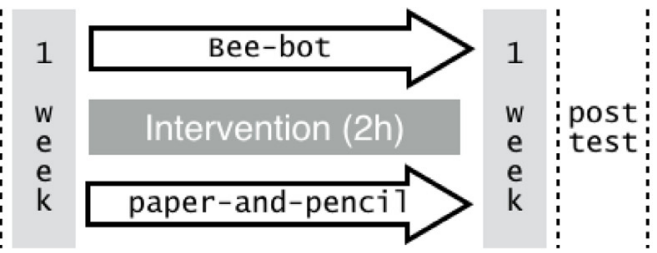

Fig. 3. Layout for the intervention design.

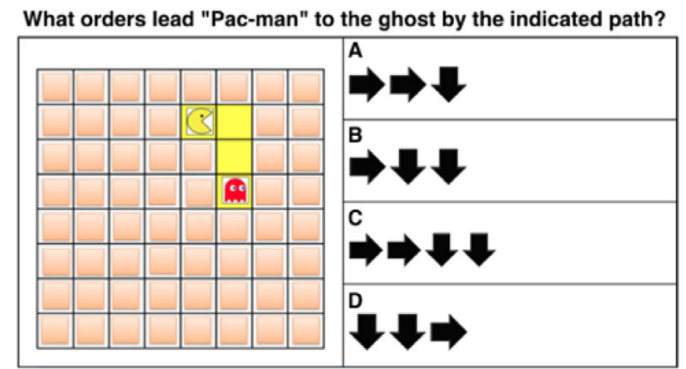

Can you identify the building with the red dot in the map?
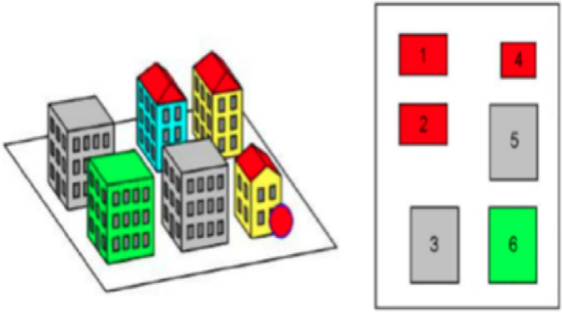

Fig. 4. Sample items used for the assessment of CT skills (left) and MR ability (right).

\subsection{Procedure}

\subsubsection{Pre-test and post-test administration}

As shown in Fig. 3, the experimental group and control groups completed the pre-test and post-test one week before and after the experimental intervention. We followed the same procedure as in van Zoest (2015) for both groups in the pre-test and posttest. To this end, each item was displayed for $30 \mathrm{~s}$ on a screen, and the participants answered on an sheet of paper. The pre-test and post-test were configured to measure the students' CT level and MR skills before and after the intervention, according to the instrument described in Section 3.3. As a result, we obtain four measurements: pre intervention CT level, post intervention CT level, pre intervention MR level and post intervention MR level. As stated by Cohen, Manion, and Morrison (2011), the use of a pre-test gives information concerning the similarity between the groups before the experiment for purposes of comparison between the post-test results on MR ability and CT skills.

\subsubsection{Intervention}

In order to measure the impact of the experimental condition, the students in both the experimental and control groups carried out the same set of map-reading tasks during the intervention phase. All the activities were referred to a large-sized paper map of a simplified city with an overlapped $15 \mathrm{~cm}$ grid (Fig. 5) with different buildings and streets depicted on it in a simplified way. Each group was provided with the same map to complete the activities. As shown in Fig. 3, the intervention took $2 \mathrm{~h}$ for both groups. Concerning the body syntonic approach, the experimental group completed the description of each route by means of the tangible interface consisting of the Bee-bot and the card-box system, presented in Fig. 2. In contrast, the control group used a traditional approach based on the use of a pencil and paper to write the body-related instructions on a sheet of paper.

Initial intervention phase. The first 20 min were devoted to explaining the basis of the map-based route finding activities. In this initial phase, the students, separated into the experimental and control groups each with their own map, were told about the procedure to solve the task. To this end, an introductory example activity was presented to the students, as follows: Your friend Mathew is at school and wants to have a swim at the beach. What route would you recommend? Write the message that you would

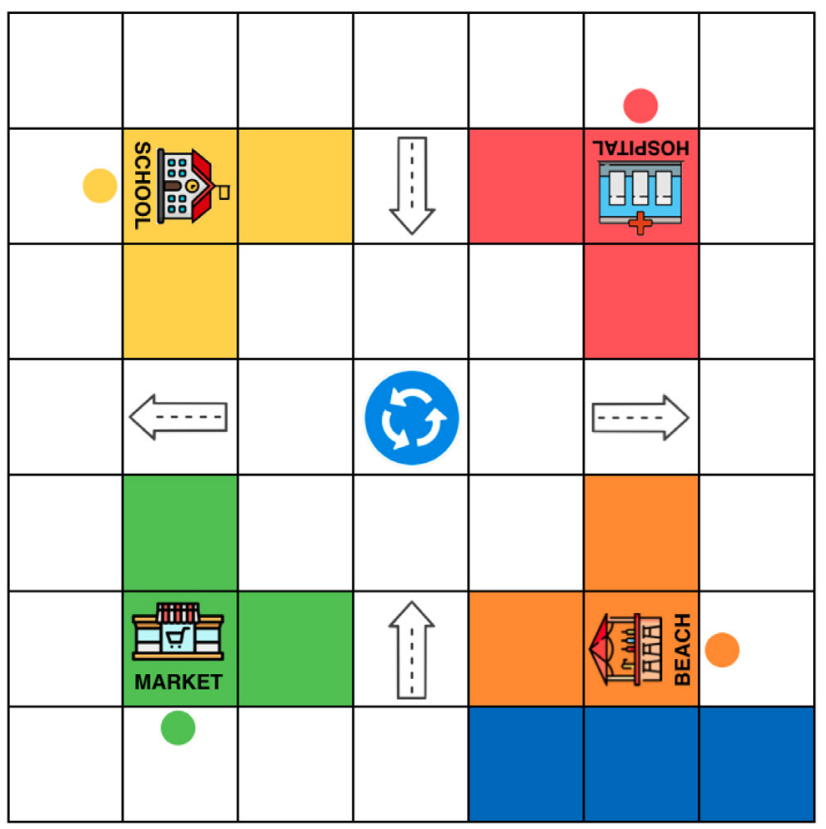

Fig. 5. $15 \times 15 \mathrm{~cm}$-grid map used in the experimental intervention. Each group, experimental and control, had their own map. (For interpretation of the references to colour in this figure legend, the reader is referred to the web version of this article.)

send him with the necessary instructions. To solve this example task the teacher and researcher explained that the grid in front of the school (the one with the yellow dot in Fig. 5) would be the starting point for planning the itinerary that students have to describe. Through this introductory task the importance of body syntonic geometry concepts was highlighted, as we describe in the following for each group.

In the experimental group, the researcher explained the basics of how to use and program Bee-bot in this initial phase. Hence, once the robot was placed at the starting point (acting as Mathew), the students were asked to discuss the instruction cards necessary to guide the robot to the beach (the square with the orange dot in Fig. 5). As described in Section 2.3.2, the researcher highlighted the need to coordinate the card instructions related 
to the Bee-bot's own movement from an external point of view, forcing the students to constantly see themselves as the robot. The researcher encouraged students to move around the map when Bee-bot was placed differently with respect to the students' orientation, in order to reduce the task difficulty. All decisions, including the initial orientation of the robot, were collaboratively decided by the students in the group. Once the route was planned in terms of the cards sequenced in the box, the instructions were transferred to Bee-bot. The movement of Bee-bot over the map served to check if the posed route was correctly planned. When the robot did not reach the goal, the students could rework the instructions posed in the card-box system.

In the control group, the classroom teacher explained the task in a paper-and-pencil environment. The participants were asked to collaboratively discuss the route planning in terms of bodyrelated instructions, following the procedure commonly proposed in textbook activities when addressing this topic. In a similar way as in the experimental group, during the introductory task the teacher emphasised the need to think about the body syntonic movements related to Mathew's from an external point of view. In this case the instructions were given in terms of bodyrelated instructions. As in the experimental group, students were encouraged to move freely around the map in order to reduce the task difficulty, if needed. The instructions were written by the students on a sheet of paper and checked by the teacher. During this initial phase the teacher corrected, if necessary, the wrong instructions proposed by the students. When a wrong instruction was detected, the teacher invited students to collaboratively debate which would be the correct option.

Group intervention phase. The rest of the intervention (lasting about $1 \mathrm{~h} 30 \mathrm{~m}$ ) was devoted to completing a set of routefinding activities. The students in the experimental and control groups were randomly assigned to different locations on their corresponding maps (the market, hospital, school and beach), forming four subgroups of three students. Each of these subgroups, called "red", "yellow", "green" and "orange", was given a set of five tasks. Initially the students were placed in front of their own colour-dotted grid (for example, the "yellow" groups were located in front of the yellow-dotted grid (facing the school building). During this phase of the intervention, the students were allowed to move freely around the map.

As explained, the experimental and control groups were given the same sets of tasks. All the tasks consisted of describing a route between two locations on the city map, and were solved in the aforementioned colour sub-groups. In Table 1 we attach the design scheme for the tasks and the concrete set of tasks for the "yellow" sub-groups as an example. The five posed tasks were arranged in difficulty from easy to hard, taking into account the influence of embodied cognition. As in the previous phase, the students had to cooperate to solve the tasks but neither help nor feedback were provided by the classroom teacher or researcher. In order that all the tasks had the same level of difficulty in all the colour sub-groups, the groups were allowed to make use of the part of the grid representing the sea on the map to move from one place to another.

The experimental group proceeded in the same way as in the initial phase: in the colour-subgroups the participants collaboratively discussed the solution to each task. Each colour-subgroup was given a Bee-bot and a card-box set. The solution was given in terms of the provided card system, and sequenced in the corresponding box before transferring it to Bee-bot. After programming their Bee-bot, the students had to check the city map to see if the robot had completed the programmed route correctly. The researcher made sure that the different Bee-bot robots did not collide with each other, controlling the progress in the tasks of the different experimental colour sub-groups. As in the previous phase, when the Bee-bot did not reach the goal, the students rework collaboratively the card-box system instructions.

The control group worked using a paper-pencil approach, as described in the initial phase, organised by the same colour subgroups, the students solved the tasks under the supervision of the classroom teacher. The route instructions were written in terms of body-related instructions on a sheet of paper and checked by the teacher. In this case, no feedback was provided by the teacher and the solution was checked by the teacher at the end of each task. Therefore, the plan could only be reformulated if any of the members of the colour sub-group realised that the instructions were not correct.

\subsection{Data analysis}

To address the research questions in this study we planned to perform pairwise comparisons and ANCOVAs. Firstly, the gains between pre-test and post-test were computed for each group. A paired t-test for each condition was carried out to assess the students' acquisition of CT and MR abilities. Secondly, ANCOVAs were employed to control initial differences between the groups. This statistical technique makes it possible to evaluate differences between experimental and control groups, taking into account any initial difference on the pre-test measurements (Ary, Jacobs, Razavieh, Sorensen, \& Walker, 2014). In particular, an ANCOVA was conducted for the post-test scores on CT and MR skills using as a covariate the pre-test scores on $\mathrm{CT}$ and MR, respectively.

All the analyses were conducted in R Team (2020), and were tested at a 0.05 level of significance. As a measurement of the effect size, the explanatory measure (Wilcox, 2012) of the effect size was reported, except for the ANCOVAs, in which case partial $\eta^{2}$ were employed (Field, Miles, \& Field, 2012).

\section{Results}

The analysis of the students' acquisition of CT skills and MR ability was carried out by means of the examination of the pretest and post-test scores. Mean scores and standard deviations of pre-test, post-test and gain for the experimental and control groups are shown in Table 2 . The results show the percentage of correct answers over the full-filled CT and MR tests - a score of 1 means 100\% correct answers-. Fig. 6 shows the comparison between the pre-test scores and the post-tests scores for the experimental and control groups. Then, the results are organised related to each research question.

\subsection{Results concerning (RQ1)}

In order to answer the first research question in this study, the differences between the pre-test and post-test scores were compared for both CT and MR. However, before analysing eventual gains in the students' CT or MR ability during the intervention, an initial analysis was conducted to identify differences in the participants' prior level in CT or MR between conditions.

Concerning CT, a Shapiro-Wilk's test indicated that the obtained scores on the pre-test were significantly non-normal for both the experimental and control groups. As a consequence, we performed a non-parametric Wilcoxon rank-sum test in order to compare the CT pre-test scores of the different groups (Wilcoxon, 1945). The statistical analysis showed that the control group obtained significantly greater CT pre-test scores $(M=0.80, S D=$ $0.23)$ than the experimental group $(M=0.58, S D=0.15)$, with a large-sized effect $(W=115.5, p=.0116, r=.52)$.

Concerning MR ability, we performed an independent t-test as the MR pre-test scores were normally distributed for each group. The comparison of the initial scores on MR reported no significant
108 
Table 1

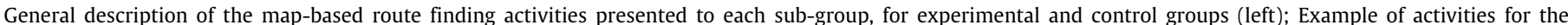
"yellow" groups (right).

\begin{tabular}{|c|c|c|c|c|}
\hline \multirow[t]{2}{*}{ Task } & \multicolumn{2}{|l|}{ General paths for all colour sub-groups } & \multicolumn{2}{|c|}{ Example tasks for the "yellow" group } \\
\hline & Route start & Route end & Route start & Route end \\
\hline 1 & Own colour-dotted grid & Colour-dotted grid on the left side & School (yellow-dotted grid) & Hospital (red-dotted grid) \\
\hline 2 & Own colour-dotted grid & Colour-dotted grid on the opposite side & School (yellow-dotted grid) & Beach (orange-dotted grid) \\
\hline 3 & Colour-dotted grid on the left side & Own colour-dotted grid & Hospital (red-dotted grid) & School (yellow-dotted grid) \\
\hline 4 & Colour-dotted grid on the right side & Colour-dotted grid on the opposite side & Market (green-dotted grid) & Beach (orange-dotted grid) \\
\hline 5 & Colour-dotted grid on the opposite side & Own colour-dotted grid & Beach (orange-dotted grid) & School (yellow-dotted grid) \\
\hline
\end{tabular}

Table 2

Summary of scores for CT and MR assessments.

\begin{tabular}{|c|c|c|c|c|c|c|c|c|c|c|c|c|c|}
\hline \multirow[t]{2}{*}{ Group } & \multirow[t]{2}{*}{$n$} & \multicolumn{6}{|l|}{$\mathrm{CT}$} & \multicolumn{6}{|c|}{ Mental rotation } \\
\hline & & $M$ & $S D$ & $M$ & $S D$ & $M$ & $S D$ & $M$ & $S D$ & $M$ & $S D$ & $M$ & $S D$ \\
\hline Experimental & 12 & 0.58 & 0.15 & 0.92 & 0.10 & 0.33 & 0.15 & 0.67 & 0.20 & 0.74 & 0.13 & 0.08 & 0.01 \\
\hline
\end{tabular}

Scale normalised to 1 for all tests.

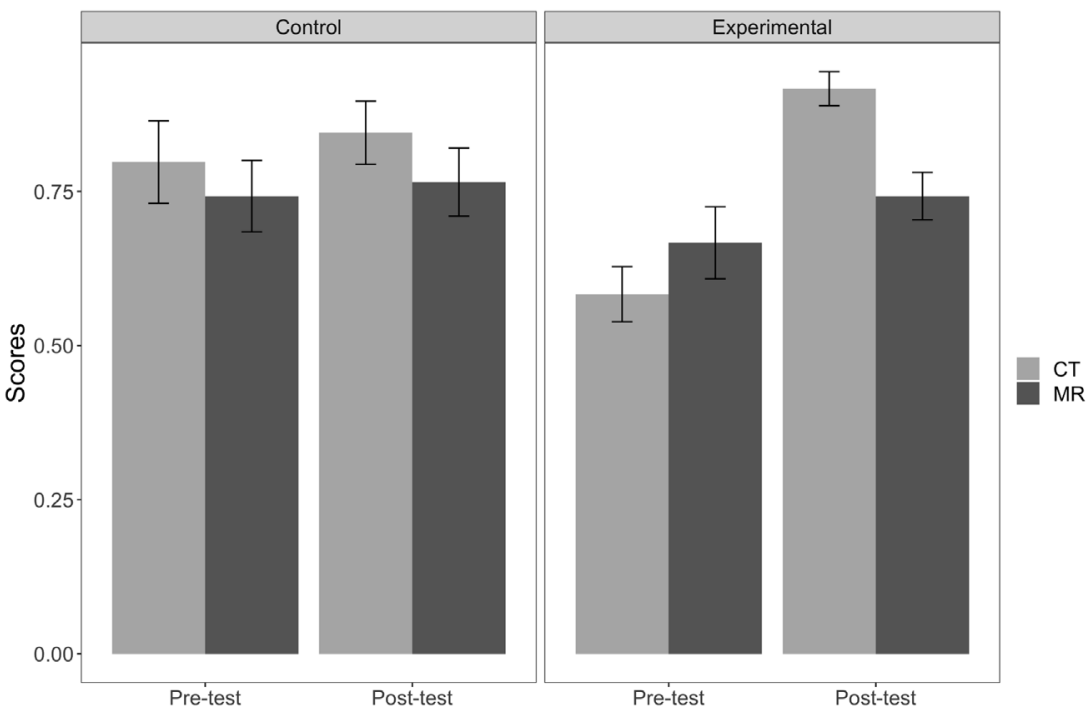

Fig. 6. Bar plots of students' $C T$ and mental rotation (MR) scores in the pre-test and the post-test for the control and experimental groups.

differences $(t(21.9)=0.91, p=.3676)$ between the performance of the control group $(M=0.74, S D=0.19)$ and the experimental group $(M=0.67, S D=0.20)$.

(RQ1) was answered by examining if there were significant differences in the CT and MR scores before and after the intervention. To this end, paired sample comparisons were conducted. In the control group, Wilcoxon signed-rank tests revealed that the students did not show significantly greater results in the post-test compared to the pre-test for both $\mathrm{CT}(p=.1736, r=.39)$ and MR ( $p=.1736, r=.39)$. However, the gains could be classified as medium-sized. In contrast, in the experimental group the posttest scores were significantly greater than those obtained in the pre-test for $\mathrm{CT}(p=.0024, r=.88)$, but not significantly greater for MR ( $p=.0579, r=.39$ ). For the experimental group, the CT and MR gains can be classified as large and medium-sized, respectively.

\subsection{Results concerning (RQ2)}

To answer the second research question an analysis of covariance (ANCOVA) on the post-test scores with the pre-test scores as a covariate was conducted for both $\mathrm{CT}$ and MR. The ANCOVA revealed a significant difference in $C T$ post-test scores in favour of experimental group compared to the control group $(F(1,21)=$
18.73, $p=.0003$; partial $\eta^{2}=0.47$ ) after controlling the effect of pre-test scores, but not in the case of $\operatorname{MR}(F(1,21)=1.84$, $p=.189$, partial $\left.\eta^{2}=0.08\right)$. According to Cohen (1988), the differences may be classified as large and medium-size for CT and $\mathrm{MR}$, respectively.

Table 3 provides a summary of the obtained results, significance and effect-size according to the research questions addressed in this study.

\section{Discussion and conclusions}

This piece of research aimed to contribute and enlarge the corpus of studies devoted to evaluating the effectiveness of robotics in education. We have focused on the potential of ER in promoting students' acquisition of spatial abilities and CT, which has been highlighted by recent studies (Anwar et al., 2019; Benitti, 2012; Coxon, 2012; Julià \& Antolì, 2018; Sisman et al., 2020). In particular, the main goal of the present study was two-fold: firstly, to analyse the gains in CT and MR ability in 8-year-old students following a two-hour ER-based intervention and traditional instruction (RQ1); and secondly, to analyse if the students who followed the ER-based intervention achieved a greater CT and MR ability level compared to traditional instruction, after controlling the students' prior CT and MR levels (RQ2). To this end, the students in both the experimental and control groups 
Table 3

Summary of results related to the research questions.

\begin{tabular}{llll}
\hline Assessment & Intervention's promotion of gains (RQ1) & & $\begin{array}{l}\text { Differences on post-test } \\
\text { scores }\end{array}$ \\
\cline { 2 - 3 } & ER-based & Traditional & \\
\hline CT & Sig. $(p=.0024)$ & Non-sig. & Sig. ${ }^{* *}(p=.0003)$ \\
& $r=.88$ & Medium effect size & Partial $\eta^{2}=0.47$ \\
& Large effect size & Large effect size \\
\hline MR & Non-sig. & Non-sig. & Non-sig. \\
& $r=.39$ & $r=.39$ & Partial $\eta^{2}=0.08$ \\
& Medium effect size & Medium effect size & Medium effect size \\
\hline
\end{tabular}

*Between experimental and control groups after controlling the initial level (pre-test).

** In favour of ER-based.

were tested on their CT skills and MR ability through map-based route finding activities. The experimental condition relied on an embodied approach, providing students with a tangible user interface composed of Bee-bot and a card-box system (a physical environment to perform tangible programming). In a two-hour intervention devoted to map-based route finding activities, the experimental group used the Bee-bot robot and the card-box system to complete the tasks. On the other hand, the control group worked using a traditional paper-and-pencil approach.

Concerning (RQ1), the results presented in this study revealed that the Bee-bot-based intervention promotes statistically significant greater gains in 8-year-old students' CT skills compared to traditional instruction. The large effect size was especially remarkable taking into account the short duration of the intervention (two hours). No conclusive results were found in relation to mental rotation. On the other hand, regarding (RQ2), the comparison of the CT post-test scores between the ER-based and paper-and-pencil groups, after controlling the students' prior CT level, points to a better performance in CT skills when the students were taught using ER. The results concerning their MR ability were inconclusive in this case, too.

The significantly different levels of the students' prior knowledge concerning CT and MR, both for control and experimental groups, may have been a limitation of this study. Although Beebot is usually employed in tasks with visuo-spatial requirements, we have not obtained conclusive results regarding the gains in MR ability for either the ER-based intervention or the traditional intervention, although a medium-size effect was found for both groups. These results can be attributed to the fact that both ER-based and traditional approaches require the children to change their reference system from an egocentric to an allocentric perspective, in order to determine the embodied necessary instructions. Although the ER-based intervention force the student to give the planning instructions exclusively in terms of the Bee-bot embodied commands, the control group instructions were also given in terms of embodied commands (verbal or pictorial) concerning another location differently positioned and oriented from the child's. Another limitation could be related to the small size sample employed in this exploratory research. In connection with this, a larger sample would make it possible to study the possible appearance of gender gaps, both in MR abilities or CT skills.

Bee-bot has been revealed to enhance CT for the 3rd grade students through map-reading tasks, in line with previous studies conducted with this floor robot (Diago et al., 2018b, 2019; Sabena, 2017). Nevertheless, the use of the tangible programming environment consisting of the card-box system together with Bee-bot could be the plausible explanation for the results obtained. In this sense, the sensory-related approach, taken into consideration with the use of Bee-bot, may have had a great bearing on the results. This was because the programming of Bee-bot in the context of map-reading tasks was based on the body syntonic movements of the robot. Thus, the card-box resource acted as a heuristic tool, by helping the child to imagine him/herself in the position of the robot through pictorial representations of its movements. Although more careful studies are necessary, our exploratory findings reinforce the benefits of the body syntonic geometry of the Bee-bot robot in educational contexts, especially related to embodied cognition and performative matters in elementary students.

Moreover, this research had provided results on the effectiveness of ER-based instruction for the development coding skills. The tangible programming environment offered by the Bee-bot robot and the card-box system has provided the children with concrete manipulation of the program. The approach followed has allowed the students to perform physical actions over the programming commands. The manipulation of command cards, through simple actions such as adding, rearranging or removing by hand, facilitated planning and debugging processes. Further studies need to be carried out in order to determine if the use of the card-box system for Bee-bot activities could enhance specific aspects of CT, as sequencing or debugging abilities. Specially, since the Bee-bot's movement cards act as an "objects-to-thinkwith", allowing children in the experimental group to validate the planned instructions after the robot's movement, as an essential step of Polya's problem-solving process. This tangible programming environment has reduced the distance between the student and the coding activity. This could be considered a major achievement, especially at ages in which formalism or coding knowledge prevents students from tackling more complex coding environments.

We can conclude that nowadays ER, and Bee-bot in particular, has been revealed not only to be an effective educational tool in providing embodied and action-based learning experiences, but also as an appropriate device for elementary students to foster CT and, perhaps, spatial abilities. Moreover, teachers and researchers have to keep in mind that ER (Bee-bot in particular) can be an important tool to take into consideration in the quest for relationships between different (or not so different) cognitive domains: the visuo-spatial, the computational and the mathematical.

\section{Funding}

This work was supported by the project GV/2019/146 from Conselleria d'Innovació, Universitats, Ciència i Societat Digital de la Generalitat Valenciana. The work of the third author was supported by Spanish MINECO projects MTM2017-83942-P and PID2020-117211GB-I00.

\section{Selection and Participation of Children}

The participants were recruited from a public school in València (Spain). The criterion used for selection was convenience sampling. The school head teacher was informed of the study details and agreed to host this study. A written informed consent was send to the parents/carers, who were informed about 
the data collected in this study. All parents/carers gave consent for their child to participate. A researcher and a teacher were in charge of the intervention and explained the details to the participants.

\section{CRediT authorship contribution statement}

Pascual D. Diago: Data curation, Investigation, Methodology, Project administration, Supervision, Writing - original draft, Writing - review \& editing. José A. González-Calero: Data curation, Investigation, Methodology, Supervision, Writing - original draft, Writing - review \& editing. Dionisio F. Yáñez: Investigation, Project administration, Supervision, Writing - original draft, Writing - review \& editing.

\section{Declaration of competing interest}

The authors declare that they have no known competing financial interests or personal relationships that could have appeared to influence the work reported in this paper.

\section{References}

Ambrosio, A. P., Almeida, L. S., Macedo, J., \& Franco, A. (2014). Exploring core cognitive skills of computational thinking. In Psychology of programming interest group annual conference 2014 (pp. 25-34).

Anwar, S., Bascou, N. A., Menekse, M., \& Kardgar, A. (2019). A systematic review of studies on educational robotics. Journal of Pre-College Engineering Education Research, 9(2), 19-42. http://dx.doi.org/10.7771/2157-9288.1223.

Ary, D., Jacobs, L., Razavieh, A., Sorensen, C., \& Walker, D. (2014). Introduction to research in education, (9th ed.). New York: Thompson/Wadsworth.

Atmatzidou, S., \& Demetriadis, S. (2016). Advancing students' computational thinking skills through educational robotics: A study on age and gender relevant differences. Robotics and Autonomous Systems, 75, 661-670. http: //dx.doi.org/10.1016/j.robot.2015.10.008.

Baroody, A. J. (2017). The use of concrete experiences in early childhood mathematics instruction, Vol. 53 (1). (pp. 43-94). Elsevier Inc., http://dx.doi.org/10. 1016/bs.acdb.2017.03.001.

Bartolini, M. G., \& Martignone, F. (2020). Manipulatives in mathematics education. In S. Lerman (Ed.), Encyclopedia of mathematics education (Second Edition). (pp. 487-494). Cham: Springer, http://dx.doi.org/10.1007/978-94007-4978-8 93.

Benitti, F. B. V. (2012). Exploring the educational potential of robotics in schools: A systematic review. Computers and Education, 58(3), 978-988. http://dx.doi. org/10.1016/j.compedu.2011.10.006.

Bers, M. U. (2008). Blocks to robots: Learning with technology in the early childhood classroom. New York: Teachers College Press.

Bers, M. U. (2018). Coding, playgrounds and literacy in early childhood education: The development of KIBO robotics and scratchjr. In IEEE global engineering education conference (pp. 2100-2108). http://dx.doi.org/10.1109/ EDUCON.2018.8363498.

Bers, M. U., Flannery, L., Kazakoff, E. R., \& Sullivan, A. (2014). Computational thinking and tinkering: Exploration of an early childhood robotics curriculum. Computers and Education, 72, 145-157. http://dx.doi.org/10.1016/j. compedu.2013.10.020.

Bers, M. U., Seddighin, S., \& Sullivan, A. (2013). Ready for robotics: Bringing together the T and E of STEM in early childhood teacher education. Journal of Technology and Teacher Education, 21(3), 355-377.

Brennan, K., \& Resnick, M. (2012). New frameworks for studying and assessing the development of computational thinking. In Annual American educational research association meeting, Vancouver, BC, Canada (pp. 1-25). Vancouver (Canada).

Çiftci, S., \& Bildiren, A. (2020). The effect of coding courses on the cognitive abilities and problem-solving skills of preschool children. Computer Science Education, 30(1), 3-21. http://dx.doi.org/10.1080/08993408.2019.1696169.

Chen, G., Shen, J., Barth-Cohen, L., Jiang, S., Huang, X., \& Eltoukhy, M. (2017). Assessing elementary students' computational thinking in everyday reasoning and robotics programming. Computers and Education, 109, 162-175. http://dx.doi.org/10.1016/j.compedu.2017.03.001.

Città, G., Gentile, M., Allegra, M., Arrigo, M., Conti, D., Ottaviano, S., et al. (2019). The effects of mental rotation on computational thinking. Computers and Education, 141, 1-11. http://dx.doi.org/10.1016/j.compedu.2019.103613.

Cohen, J. (1988). Statistical power analysis for the behavioral sciences (2nd ed.). New York: Academic Press.

Cohen, L., Manion, L., \& Morrison, K. (2011). Research methods in education. New York: Routledge.
Cook, T. D., \& Campbell, D. T. (1979). Quasi-experimentation: Design \& analysis issues in field settings. Boston, MA: Houghton Mifflin.

Coxon, S. V. (2012). The malleability of spatial ability under treatment of a FIRST lego league-based robotics simulation. Journal for the Education of the Gifted, 35(3), 291-316. http://dx.doi.org/10.1177/0162353212451788.

Davis, B., \& The Spatial Reasoning Study Group (Eds.), (2015). Spatial reasoning in the early years. Principles, assertions, and speculations. New York, NY: Routledge.

Di Lieto, M. C., Inguaggiato, E., Castro, E., Cecchi, F., Cioni, G., Dell'Omo, M., et al. (2017). Educational robotics intervention on executive functions in preschool children: A pilot study. Computers in Human Behavior, 71, 16-23. http://dx.doi.org/10.1016/j.chb.2017.01.018.

Diago, P. D., Arnau, D., \& González-Calero, J. A. (2018a). Desarrollo del pensamiento computacional en Educación Infantil mediante la resolución de problemas en entornos tecnológicos. In R. Cózar, \& J. A. González-Calero (Eds.), Tendencias y tecnologías emergentes en investigación e innovación educativa (pp. 197-214). Barcelona: Editorial Graó.

Diago, P. D., Arnau, D., \& González-Calero, J. A. (2018b). Elementos de resolución de problemas en primeras edades escolares con bee-bot. Edma 0-6: Educación Matemática en la Infancia, 7(1), 12-41.

Diago, P. D., González-Calero, J. A., \& Arnau, D. (2019). Fundamentals of the design of a technological environment for the study of the problem-solving habilities in early childhood. Research in Education and Learning Innovation Archives, (22), 58-76. http://dx.doi.org/10.7203/realia.22.14113.

Diezmann, C. M., \& Lowrie, T. (2008). Assessing primary students' knowledge of maps. In O. Figueras, \& A. Sepúlveda (Eds.), Proceedings of the joint meeting of PME 32 and PME-NA XXX, (Vol. 2) (pp. 415-421). Morelia: PME.

Eguchi, A. (2014). Educational robotics for promoting 21st century skills. Journal of Automation, Mobile Robotics \& Intelligent Systems, 8(1), 5-11. http://dx.doi. org/10.14313/JAMRIS_1-2014/1.

Field, A., Miles, J., \& Field, Z. (2012). Discovering statistics using R. SAGE Publications Ltd, URL https://studysites.uk.sagepub.com/dsur/study/default. htm.

Freeman, A., Adams Becker, S., Cummins, M., Davis, A., \& Hall Giesinger, C. (2017). NMC/CoSN horizon report: 2017 K-12 edition. Austin, Texas: Austin, Texas, 978-0-9988650-3-4.

González-Calero, J. A., Cózar, R., Villena, R., \& Merino, J. M. (2019). The development of mental rotation abilities through robotics-based instruction: An experience mediated by gender. British Journal of Educational Technology, 50(6), 3198-3213. http://dx.doi.org/10.1111/bjet.12726.

Govind, M., Relkin, E., \& Bers, M. U. (2020). Engaging children and parents to code together using the scratchjr app. Visitor Studies, 1-20. http://dx.doi.org/ $10.1080 / 10645578.2020 .1732184$.

Grover, S., Jackiw, N., \& Lundh, P. (2019). Concepts before coding: nonprogramming interactives to advance learning of introductory programming concepts in middle school. Computer Science Education, 29(2-3), 106-135. http://dx.doi.org/10.1080/08993408.2019.1568955.

Grover, S., \& Pea, R. (2013). Computational thinking in K-12: A review of the state of the field. Educational Researcher, 42(1), 38-43. http://dx.doi.org/10. 3102/0013189X12463051.

Gutiérrez, A. (1996). Visualization in 3-dimensional geometry: In search of a framework. In Proceedings of the 20th PME conference, (Vol. 1), València, España (pp. 3-19).

Hamilton, M., Clarke-Midura, J., Shumway, J. F., \& Lee, V. R. (2020). An emerging technology report on computational toys in early childhood. Technology, Knowledge and Learning, 25(1), 213-224. http://dx.doi.org/10.1007/s10758019-09423-8.

Hawes, Z., Tepylo, D., \& Moss, J. (2015). Developing spatial thinking. In B. Davis, \& The Spatial Reasoning Study Group (Eds.), Spatial reasoning in the early years. Principles, assertions, and speculations (pp. 29-44). New York, NY: Routledge.

Highfield, K. (2010). Robotic toys as a catalyst for mathematical problem solving. Australian Primary Mathematics Classroom, 15(2), 22-27.

Hodgen, J., Foster, C., Marks, R., \& Brown, M. (2018). Evidence for review of mathematics teaching: improving mathematics in key stages two and three. London, UK: Education Endowment Foundation.

Horn, M. S., Crouser, R. J., \& Bers, M. U. (2012). Tangible interaction and learning: The case for a hybrid approach. Personal and Ubiquitous Computing, 16(4), 379-389. http://dx.doi.org/10.1007/s00779-011-0404-2.

Hussain, S., Lindh, J., \& Shukur, G. (2006). The effect of LEGO training on pupils' school performance in mathematics, problem solving ability and attitude: Swedish data. Educational Technology and Society, 9(3), 182-194.

Inchaustegui, Y. A., \& Alsina, A. (2020). Learning patterns at three years old: Contributions of a learning trajectory and teaching itinerary. Australasian Journal of Early Childhood, 45(1), 14-29. http://dx.doi.org/10.1177/ 1836939119885310.

Julià, C., \& Antolì, J. O. (2018). Enhancing spatial ability and mechanical reasoning through a STEM course. International Journal of Technology and Design Education, 28(4), 957-983. http://dx.doi.org/10.1007/s10798-017-9428-x. 
Kazakoff, E. R., Sullivan, A., \& Bers, M. U. (2013). The effect of a classroombased intensive robotics and programming workshop on sequencing ability in early childhood. Early Childhood Education Journal, 41(4), 245-255. http: //dx.doi.org/10.1007/s10643-012-0554-5.

Kim, C., Kim, D., Yuan, J., Hill, R. B., Doshi, P., \& Thai, C. N. (2015). Robotics to promote elementary education pre-service teachers' STEM engagement, learning, and teaching. Computers and Education, 91, 14-31.

Lakoff, G., \& Núñez, R. (2000). where mathematics comes from: How the embodied mind brings mathematics into being. New York: Basic Books.

Lindh, J., \& Holgersson, T. (2007). Does lego training stimulate pupils' ability to solve logical problems? Computers and Education, 49(4), 1097-1111. http: //dx.doi.org/10.1016/j.compedu.2005.12.008.

Lohman, D. F. (1996). Spatial ability and g. In Human abilities: Their nature and assessment (pp. 97-116). Hillsdale, NJ: Erlbaum.

M., R., F., M., R., B., R., B., V., C., K., K., et al. (1998). Digital manipulatives: new toys to think with. In Proceedings of the CHI'98 conference on human factors in computing systems (pp. 281-287). Los Ángeles, California: ACM Press, http://dx.doi.org/10.1145/274644.274684.

McNeill, D. (1992). Hand and mind: What gestures reveal about thought. Chicago: University of Chicago Press.

McNeill, D. (2005). Gesture and thought. Chicago: University of Chicago Press.

McNerney, T. S. (2004). From turtles to tangible programming bricks: Explorations in physical language design. Personal and Ubiquitous Computing, 8(5), 326-337. http://dx.doi.org/10.1007/s00779-004-0295-6.

Merino-Armero, J. M., González-Calero, J. A., Cózar-Gutiérrez, R., \& VillenaTaranilla, R. (2018). Computational thinking initiation. An experience with robots in primary education. Journal of Research in Science, Mathematics and Technology Education, 1(2), 181-206. http://dx.doi.org/10.31756/jrsmte.124.

National Council of Teachers of Mathematics (2000). Principles and standards for school mathematics. Reston, VA: NCTM.

Nemirovsky, R., \& Ferrara, F. (2009). Mathematical imagination and embodied cognition. Educational Studies in Mathematics, 70(2), 159-174. http://dx.doi. org/10.1007/s10649-008-9150-4.

Papert, S. (1980). Mindstorms: Children, computers and powerful ideas. Basic Books.

Perlman, R. (1976). Using computer technology to provide a creative learning environment for preschool children. In MIT AI lab memo no. 360/Logo memo, N. 24 (pp. 1-13). Cambridge: MIT AI Lab, URL http://18.7.29.232/handle/1721. $1 / 5784$.

Peter, M., Glück, J., \& Beiglböck, W. (2010). Map understanding as a developmental marker in childhood. Journal of Individual Differences, 31(2), 64-67. http://dx.doi.org/10.1027/1614-0001/a000011.

Radford, L. (2009). Why do gestures matter? Sensuous cognition and the palpability of mathematical meanings. Educational Studies in Mathematics, 70(2), 111-126. http://dx.doi.org/10.1007/s10649-008-9127-3.

Reilly, D., Neumann, D. L., \& Andrews, G. (2017). Visual-spatial ability in STEM education: Transforming research into practice. In M. S. Khine (Ed.), Visualspatial ability in STEM education: Transforming research into practice (pp. 195-224). Cham: Springer, http://dx.doi.org/10.1007/978-3-319-44385-0.

Rodríguez-Martínez, J. A., González-Calero, J. A., \& Sáez-López, J. M. (2020). Computational thinking and mathematics using scratch: an experiment with sixth-grade students. Interactive Learning Environments, 28(3), 316-327. http: //dx.doi.org/10.1080/10494820.2019.1612448.

Román-González, M., Pérez-González, J. C., \& Jiménez-Fernández, C. (2017). Which cognitive abilities underlie computational thinking? Criterion validity of the computational thinking test. Computers in Human Behavior, 72, 678-691. http://dx.doi.org/10.1016/j.chb.2016.08.047.

Sabena, C. (2017). Early child spatial development: A teaching experiment with programmable robots. In G. Aldon, F. Hitt, L. Bazzini, \& U. Gellert (Eds.), Mathematics and technology, advances in mathematics education (pp. 13-30). Cham, Switzerland: Springer International Publishing, http://dx.doi.org/10. 1007/978-3-319-51380-5.

Schina, D., Esteve-Gonzalez, V., \& Usart, M. (2021). Teachers' perceptions of beebot robotic toy and their ability to integrate it in their teaching. In L. W., M. M., K. G., B. R., \& O. D. (Eds.), Robotics in education. RiE 2020. Advances in intelligent systems and computing, Vol. 1316 (pp. 121-132). Cham: Springer, http://dx.doi.org/10.1007/978-3-030-67411-3_12.
Shepard, R. N., \& Metzler, J. (1971). Mental rotation of three-dimensional objects. Science, 171(3972), 701-703. http://dx.doi.org/10.1126/science.171.3972.701.

Shute, V. J., Sun, C., \& Asbell-Clarke, J. (2017). Demystifying computational thinking. Educational Research Review, 22, 142-158. http://dx.doi.org/10.1016/ j.edurev.2017.09.003.

Sisman, B., Kucuk, S., \& Yaman, Y. (2020). The effects of robotics training on children's spatial ability and attitude toward STEM. International Journal of Social Robotics, http://dx.doi.org/10.1007/s12369-020-00646-9.

Stoeckelmayr, K., Tesar, M., \& Hofmann, A. (2011). Kindergarten children programming robots: A first attempt. International Conference on Robotics in Education, 185-192.

Strawhacker, A., \& Bers, M. U. (2015). "I want my robot to look for food": Comparing kindergartner's programming comprehension using tangible, graphic, and hybrid user interfaces. International Journal of Technology and Design Education, 25(3), 293-319. http://dx.doi.org/10.1007/s10798-014-9287-7.

Sullivan, A., \& Bers, M. U. (2016). Robotics in the early childhood classroom: learning outcomes from an 8-week robotics curriculum in pre-kindergarten through second grade. International Journal of Technology and Design Education, 26(1), 3-20. http://dx.doi.org/10.1007/s10798-015-9304-5.

Sullivan, A., Strawhacker, A., \& Bers, M. U. (2017). Dancing, drawing, and dramatic robots: Integrating robotics and the arts to teach foundational STEAM concepts to Young children. In M. S. Khine (Ed.), Robotics in STEM education: Redesigning the learning experience (pp. 231-260). Springer International Publishing, http://dx.doi.org/10.1007/978-3-319-57786-9_10.

Tall, D. (2013). how humans learn to think mathematically. New York: Cambridge University Press, http://dx.doi.org/10.1017/cbo9781139565202.

Team, R. C. (2020). R: A language and environment for statistical computing Vienna, Austria: R Foundation for Statistical Computing, URL https://www.rproject.org/.

Tzuriel, D., \& Egozi, G. (2010). Gender differences in spatial ability of young children: The effects of training and processing strategies. Child Development, 81(5), 1417-1430. http://dx.doi.org/10.1111/j.1467-8624.2010.01482.x.

van Zoest, V. (2015). Relationship between video gaming and spatial thinking skills of children 8 to 10 years old. Wageningen: Wageningen University and Research Centre.

Verner, I. M. (2004). Robot manipulations: A synergy of visualization, computation and action for spatial instruction. International Journal of Computers for Mathematical Learning, 9(2), 213-234. http://dx.doi.org/10.1023/B:IJCO. 0000040892.46198.aa.

Weintrop, D., Coenraad, M., Palmer, J., \& Franklin, D. (2019). The teacher accessibility, equity, and content (TEC) rubric for evaluating computing curricula. ACM Transactions on Computing Education, 20(1), 1-30. http://dx. doi.org/10.1145/3371155.

Wilcox, R. R. (2012). Introduction to robust estimation and hypothesis testing (3rd). Boston: Academic Press.

Wilcoxon, F. (1945). Individual comparisons by ranking methods. Biometrics Bulletin, 1, 80-83.

Wing, J. M. (2006). Computational thinking. Communications of the ACM, 49(3), 33-35. http://dx.doi.org/10.1145/1118178.1118215.

Wing, J. M. (2010). Computational thinking - what and why? The Link Magazine, $1-6$.

Wing, J. M. (2014). Computational thinking benefits society [blog post].

Wyeth, P. (2008). How young children learn to program with sensor, action, and logic blocks. Journal of the Learning Sciences, 17(4), 517-550. http: //dx.doi.org/10.1080/10508400802395069. 